\title{
Nutrient-Dependent Efficacy of the Antifungal Protein YvgO Correlates to Cellular Proliferation Rate in Candida albicans 3153A and Byssochlamys fulva $\mathrm{H25}$
}

\author{
David C. Manns · John J. Churey • \\ Randy W. Worobo
}

Published online: 13 September 2014

(C) Springer Science+Business Media New York 2014

\begin{abstract}
YvgO}$ is a recently characterized antifungal protein isolated from Bacillus thuringiensis SF361 that exhibits a broad spectrum of activity and $\mathrm{pH}$ stability. Customized colorimetric metabolic assays based on standard broth microdilution techniques were used to determine the variable tolerance of Byssochlamys fulva $\mathrm{H} 25$ and Candida albicans 3153A to YvgO exposure under select matrix conditions impacting cellular proliferation. Normalization of the solution $\mathrm{pH}$ after antifungal challenge expanded the available $\mathrm{pH}$ range under consideration allowing for a comprehensive in vitro assessment of $\mathrm{YvgO}$ efficacy. Indicator susceptibility was examined across an array of elementary growth-modifying conditions, including media $\mathrm{pH}$, incubation temperature, ionic strength, and carbohydrate supplementation. Under suboptimal temperature and $\mathrm{pH}$ conditions, the indicator growth rate reduced, and $\mathrm{YvgO}$-mediated susceptibility was attenuated. While $\mathrm{YvgO}$ association but not efficacy was somewhat influenced by solution ionic strength, carbohydrate supplementation was shown to be the most influential susceptibility factor, particularly for C. albicans. Although the specific choice of carbohydrate/nutrient supplement dictated the extent of enhanced $\mathrm{YvgO}$ efficacy, D-glucose additionally improved the association between antifungal
\end{abstract}

Electronic supplementary material The online version of this article (doi:10.1007/s12602-014-9167-1) contains supplementary material, which is available to authorized users.

D. C. Manns · J. J. Churey $\cdot$ R. W. Worobo $(\bowtie)$

Department of Food Science, New York State Agricultural

Experiment Station, Cornell University, 630 West North Street,

Geneva, NY 14456, USA

e-mail: rww8@cornell.edu

D. C. Manns

e-mail: dcm38@cornell.edu and target. Indeed, when exposed to $\mathrm{YvgO}$ under conditions that lead to increased cellular proliferation, both indicators displayed a stronger association and susceptibility to $\mathrm{YvgO}$ when compared to carbohydrate-deprived media or suboptimal incubation environments. With further study, YvgO may have the capacity to function as a prophylaxis for food safety and preservation, as well as a pharmaceutical agent against opportunistic fungal pathogens either independently or in combination with other established treatments applied to both livestock and human health concerns.

Keywords Fungal inhibition $\cdot$ XTT assay $\cdot$ Heat-resistant mold $\cdot$ Human fungal pathogen

\section{Introduction}

Current antifungal methodologies for the clinical and food safety fields are limited due to low therapeutic thresholds, poor stability or efficacy, and increasing resistance [11, 14, 24]. As with antibacterial compounds, the need for new antifungal compounds is becoming more relevant as clinical and food-processing challenges continue to escalate. In addition to producing the bacteriocin Thurincin $\mathrm{H}$ [30], Bacillus thuringiensis SF361 produces and secretes $\mathrm{YvgO}$, a novel proteinaceous agent showing select antifungal activity toward several genera of filamentous fungi including Aspergillus, Byssochlamys, and Penicillium as well as the pathogenic yeast Candida albicans [20]. To gain a better understanding of the biological activity of YvgO, two primary indicators, Byssochlamys fulva $\mathrm{H} 25$ and C. albicans 3153A, were selected due to their high susceptibility, their relevance to either food or clinical applications, and their dissimilar morphology. 
In our previous work, we reported that $\mathrm{YvgO}$ is stable for at least 2 weeks at physiological and ambient temperatures and is neither acid nor alkali labile, surviving for at least 2 weeks in solutions ranging from $\mathrm{pH} 3$ through 12 [20]. In this initial study, after incubation, the activity of YvgO was assessed through the dilution of titers upon solid nutrient agar, rather than directly at the incubation test conditions. Up to this point, the functionality of $\mathrm{YvgO}$ at variable matrix composition or solution $\mathrm{pH}$ is unknown. As such, the aims of the current study were threefold: (1) determine the differential efficacy of $\mathrm{YvgO}$ against the chosen indicators under variable solution $\mathrm{pH}$, nutrient supplementation, and other growth-modifying conditions, (2) accomplish the previous goal using a straightforward analytical method that can be readily adapted for proteinaceous and variable pH systems, and (3) correlate specific indicator response metrics to $\mathrm{YvgO}$ efficacy in an effort to elucidate potential means of biological activity.

To meet objective one, the choice and style of assessment outlined in objective two becomes critical. In regards to the second objective, standardized broth dilution methods do provide defined guidelines for determining breakpoint parameters and quality control measures but are only validated for select antifungal agents against a limited set of indicators [2]. Since we are interested in YvgO's effect upon select indicators under specific growth conditions, we will need to be free from such narrow constraints and have instead opted for an assay that gives a more detailed response to antifungal activity. Similar to other colorimetric susceptibility assays [16, 18], tetrazolium salt-based methods are essentially a broth microdilution assay utilizing a colorimetric indicator for the quantitative comparison of antimicrobial susceptibility, providing a more detailed assessment over measurements of titers, diffusion techniques, or broth dilution methods $[4,7,13,21]$ while also suitably comparing to established standardized broth dilution methods [5, 6] outlined by the Clinical and Laboratory Standards Institute (CLSI). To that end, an assay involving the reduction of XTT (2,3-bis-(2-methoxy-4-nitro-5-sulfophenyl)-2H-tetrazolium-5-carboxanilide) [23] has been optimized and modified to best assess the cytotoxic efficacy of YvgO throughout an extended range of matrix considerations against both model indicators. In addition, this assay will provide essential quantitative measures of $\mathrm{EC}_{50}, \mathrm{YvgO} /$ indicator association, and minimum inhibitory concentration (MIC), permitting a more thorough characterization of $\mathrm{YvgO}$ efficacy. This study does not attempt to redefine standard antimicrobial testing procedures. Our methodology requires the use of modified media formulations and growth conditions that would need to deviate from prescribed CLSI approaches. Also, as we are not comparing the efficacy of $\mathrm{YvgO}$ against other antifungal compounds, standard visual end point CLSI approaches to antimicrobial testing have been used for comparative and validation purposes only.

During the initial characterization of such a novel antifungal compound with diverse applications ranging from pharmaceutical agent to food protectant, developing an understanding of its biological activity against sensitive fungal strains is required. To initiate this line of research, variable $\mathrm{YvgO}$ susceptibility was quantified based on the influence of select matrix conditions typical of physiological and food-based systems that affect indicator growth, which as will be shown, affect YvgO efficacy.

\section{Materials and Methods}

Microbial Indicators, Media, and YvgO Antifungal Protein Production

Two microorganisms of differential morphology but elevated susceptibility were chosen to serve as the indicators used to assess YvgO efficacy. A B. fulva H25 spore crop $\left(10^{5}\right.$ spores $\left./ \mathrm{ml}\right)$ was prepared and stored as described previously [20]. C. albicans $3153 \mathrm{~A}$ was maintained on potato dextrose agar (3.9 \% PDA, BD Difco; Franklin Lakes, NJ USA) acidified to $\mathrm{pH} 3.5$ with $10 \%$ tartaric acid. To develop an active culture, a single colony was transferred to 5 mls of tryptic soy broth (3\% TSB, BD Difco; Franklin Lakes, NJ USA) and incubated for $16 \mathrm{~h}$ at $30^{\circ} \mathrm{C}$. These media were chosen as they each can be simply modified as needed to exploit potential differences in efficacy observed upon each indicator being studied.

The semi-purified ( $>95 \%$ purity) ammonium sulfate precipitation fraction (40\% saturation of the supernatant adjusted to $\mathrm{pH}$ 6) of $\mathrm{YvgO}$ was prepared as previously described [20], resuspended in Milli-Q water (Millipore Corporation; Bedford, MA USA), and generated within 1 day prior to use. The absence of synergistic or complementary activity in the semi-purified preparations was verified against HPLC-purified YvgO.

Susceptibility assays were carried out using several media (BD Difco; Franklin Lakes, NJ USA): [1] CAA, $3.0 \%$ Casamino acids supplemented with $1.5 \%$ yeast extract, [2] PDB, $2.4 \%$ potato dextrose broth; and [3] TSB, $3.0 \%$ tryptic soy broth. Precise $\mathrm{pH}$ alterations and/or carbohydrate supplementation were made as necessary. The media for all optimizations and assays were filter sterilized through a $0.2-\mu \mathrm{m}$ polyethersulfone (PES) membrane (Millipore Corporation; Bedford, MA USA).

\section{XTT and Menadione}

The XTT assay typically functions better when the reduction of the XTT substrate occurs in the presence of an 
electron-coupling reagent such as menadione (22). XTT (Sigma-Aldrich; ST. Louis, MO USA) was dissolved in Milli-Q water to a final working concentration of $2 \mathrm{mg} / \mathrm{ml}$. A $25 \mathrm{mM}$ solution of menadione (Sigma-Aldrich; ST. Louis, MO USA) was prepared directly in acetone and diluted in Milli-Q water to a final working concentration of $250 \mu \mathrm{M}$. Each solution was filtered through a $0.2-\mu \mathrm{m}$ PES membrane and stored in amber vials at $4{ }^{\circ} \mathrm{C}$. Equal volumes of each component was warmed to room temperature and combined immediately prior to use.

\section{Experimental Design and Optimization of XTT Parameters}

Assays were carried out in triplicate using sterile 96-well flat bottom polystyrene microtiter plates (Costar; Corning, NY USA) and analyzed using an MRXTC Revelation microtiter plate reader (Dynex Technologies, Chantilly, VA USA) set at $490 \mathrm{~nm}$ for XTT/menadione absorbance and $600 \mathrm{~nm}$ for XTT-independent monitoring of fungal cell growth and calculation of cellular proliferation rates. While incubations for all stages of optimization were initially examined at both 30 and $37^{\circ} \mathrm{C}$, subsequent optimized analyses were carried out at $30^{\circ} \mathrm{C}$.

During XTT assay optimization, initial indicator densities were varied from $10^{2}$ to $10^{5} \mathrm{cfu} / \mathrm{ml}$, while XTT and menadione concentrations were assessed from 25 to $200 \mu \mathrm{g} / \mathrm{ml}$ and 0 to $125 \mu \mathrm{M}$, respectively. Indicator growth periods and post XTT incubation periods were optimized based on the differential growth rate between each indicator. In order to assess the amount of growth after XTT/menadione addition all wells were examined visually and at $600 \mathrm{~nm}$ in an XTT-independent fashion. In doing so, there is a direct comparison between the quantitative XTT assay and a visual method of detection dictated by the CLSI [4, 21, 26]. Incubations for the optimizations were performed with CAA media adjusted to $\mathrm{pH} 6$.

The optimized XTT assay consisted of $150 \mu \mathrm{l}$ aliquot of $10^{5} \mathrm{cfu} / \mathrm{ml}$ indicator combined with $50 \mu \mathrm{l}$ of the twofold serially diluted antifungal preparation. Fifty microliters of sterile water in place of the antifungal served as the unrestricted growth control (theoretical maximum), while sterile media in place of the inoculant served as the negative growth control (theoretical minimum). B. fulva spores were incubated at $30{ }^{\circ} \mathrm{C}$ for $24 \mathrm{~h}$, while $C$. albicans was incubated at $30{ }^{\circ} \mathrm{C}$ for $6 \mathrm{~h}$. Following incubation, $50 \mu \mathrm{l}$ of XTT/menadione was added (final concentrations $200 \mu \mathrm{g} /$ $\mathrm{ml}, 25 \mu \mathrm{M}$, respectively) and incubated for $2 \mathrm{~h}$ (B. fulva) or $30 \mathrm{~min}$ (C. albicans). Plates were read after a $15 \mathrm{~min}$ incubation following a $25 \mu \mathrm{l} 1 \mathrm{M}$ phosphate buffer addition, described below.
Effect of Matrix pH on the Reliability and Feasibility of the XTT Assay

The complication with assessing a $\mathrm{pH}$-variable system with tetrazolium salts is twofold: (1) the absorbance from reduced XTT is maximal at $\mathrm{pH} 6.2$, decreasing substantially at lower $\mathrm{pH}$ values and (2) the background absorbance due to matrix interference is unacceptably high at elevated $\mathrm{pH}$. To adapt the technique to suit the current study's needs and expand the general utility of the assay, the $\mathrm{pH}$ of the base media was varied integrally from 3 to 10 to assess the growth rate of each indicator and determine the $\mathrm{pH}$-sensitive effectiveness of XTT/menadione. The indicator growth as measured at $600 \mathrm{~nm}$, matrix background absorbance, and XTT-generated signal of each $\mathrm{pH}$ adjusted media was compared against a second set of wells receiving $25 \mu \mathrm{l}$ of $1 \mathrm{M}$ phosphate buffer ( $\mathrm{pH}$ 6.2), added either before or after XTT/menadione incubation. Duplicate XTT-free wells were inspected visually and also measured at $600 \mathrm{~nm}$ as an XTT-independent assessment of fungal growth and YvgO susceptibility. This led to the final optimized procedure described in the previous section.

YvgO Efficacy as Dictated by Incubation Media pH

Due to growth restrictions, the $\mathrm{pH}$-dependent susceptibility of each indicator was determined integrally from $\mathrm{pH} 3$ to 8 in CAA media. The starting concentration of the YvgO dilution series was $25 \mu \mathrm{g} / \mathrm{ml}$ and $1,600 \mu \mathrm{g} / \mathrm{mL}$ for $B$. fulva and $C$. albicans, respectively. It was determined experimentally that the $\mathrm{pH}$ of each well did not vary significantly due to antifungal addition or indicator growth during the assay time span.

YvgO Efficacy due to Media and Carbohydrate Supplement

For each indicator, three primary media were used to assess susceptibility: (1) CAA, (2) PDB, and (3) TSB, as described earlier. In addition, both indicators were tested against CAA media supplemented with either 5 or $20 \mathrm{~g} / \mathrm{L}$ of either D-glucose or mannose (Fisher Scientific; Pittsburgh, PA USA). Additionally, each of these formulations were tested integrally from $\mathrm{pH} 3$ to 8 .

YvgO Efficacy due to Altered Solution Ionic Strength

In a similar fashion, the base CAA media was supplemented with increasing concentrations of sodium chloride (Fisher Scientific; Pittsburgh, PA USA). The ionic strength of the media was varied from 25 to $200 \mathrm{mM}$. Throughout this range, indicator susceptibility was assessed at $\mathrm{pH} 3.5$, 
6.0 , and 7.4 in the presence or absence of $20 \mathrm{~g} / \mathrm{L} \mathrm{D}$-glucose or mannose.

\section{Data Analysis and Statistical Interpretation}

Indicator proliferation was described as normalized percent growth, the maximum defined as the YvgO-free control. The fungi-free wells served as the zero-signal background. The sigmoidal curves generated from the $\mathrm{YvgO}$-mediated growth response were analyzed using a nonlinear, four parameter $\mathrm{E}_{\max }$ regression model [8-10] with a variable slope and no preset constrictions on sigmoidal curve minimums or maximums, described by the equation:

$y=a+(b-a) /\left(1+10^{((x-c) * d)}\right)$

where "a" is the theoretical minimum of the sigmoidal curve; "b" is its theoretical maximum; "c" is the $\log \mathrm{EC}_{50}$ (the concentration of antifungal required to reduce growth by $50 \%$ from the theoretical maximum); and " $\mathrm{d}$ " is the slope, a convenient measure of the strength of association between the indicator and $\mathrm{YvgO}$. As mathematically described, the slope would generate a negative value. However, for clarity, all slopes are given as absolute values.

Sigmoidal curves were described as an average of three independent experiments each performed in triplicate, with a standard deviation about the mean. $\mathrm{EC}_{50}$ and slopes were statistically described using the $95 \%$ confidence interval (CI) range. The lowest concentration of $\mathrm{YvgO}$ restricting growth to no more than $5 \%$ over the background control was defined as the MIC. These were additionally confirmed visually using simple broth dilution methods. Treatment comparisons were performed using one-way analysis of variance (ANOVA) and the Tukey's HSD test. Correlations between solution $\mathrm{pH}$, susceptibility within data sets, and between YvgO efficacy and cellular proliferation were described using Spearman's rank correlation test.

\section{Results and Discussion}

There were no significant differences during optimization or subsequent treatments within trials incubated at 30 and $37^{\circ} \mathrm{C}$. Therefore, for ease of explanation, and to ensure that hyphal growth in $C$. albicans is prevented, all presented data reflects the $30{ }^{\circ} \mathrm{C}$ incubation trials. However, when compared between 30 and $37{ }^{\circ} \mathrm{C}$, elevated incubation temperatures resulted in decreased indicator doubling times, resulting in decreased $\mathrm{EC}_{50}$ and $\mathrm{MIC}$ values. Details for the XTT optimization protocol follow the $\mathrm{YvgO} /$ microbe interaction study.

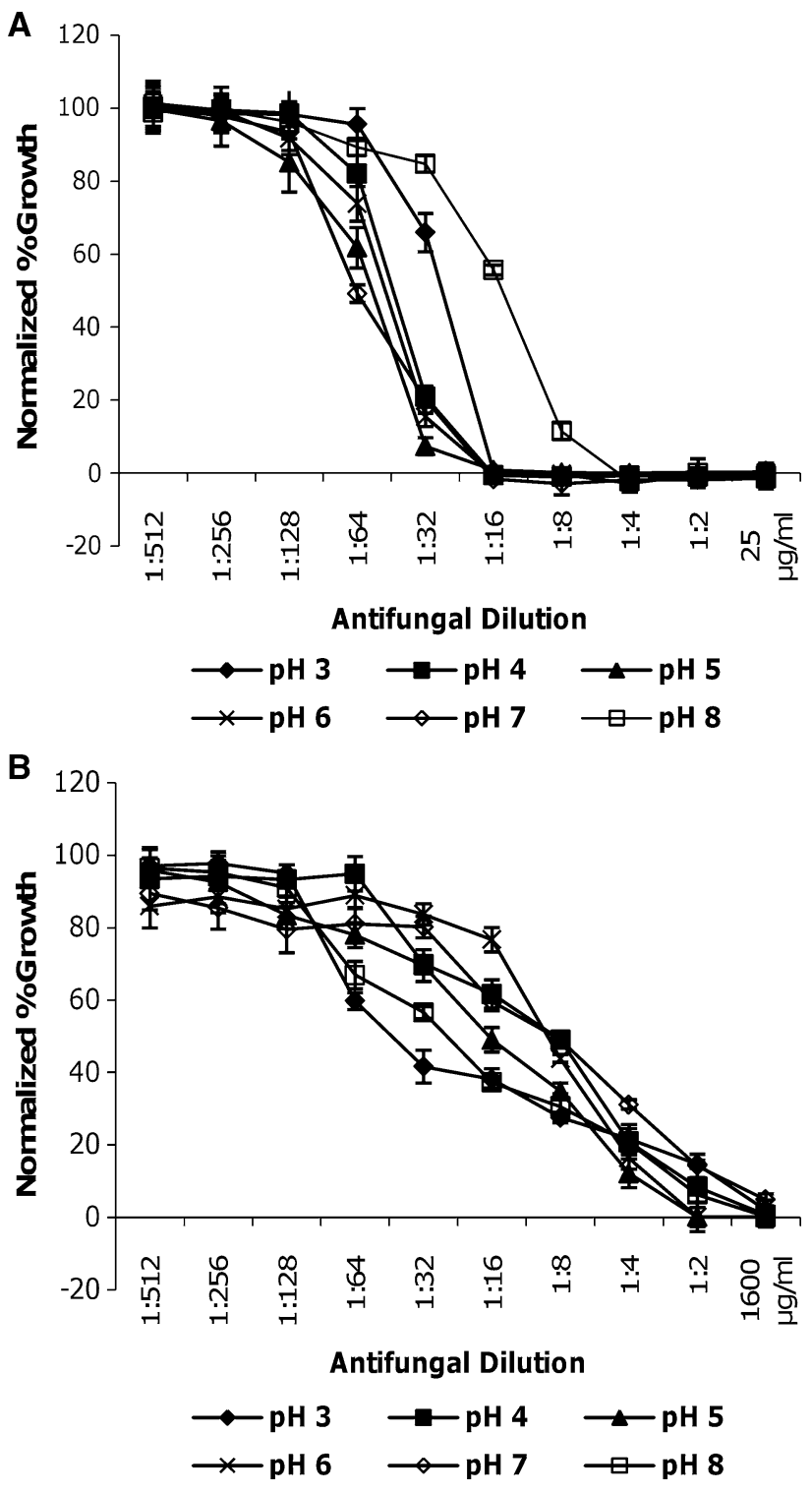

Fig. 1 XTT-determined growth curves as influenced by incubation media $\mathrm{pH}$ generated by B. fulva $\mathrm{H} 25$ (a) and C. albicans 3153A (b) exposed to serially diluted additions of the $\mathrm{YvgO}$ antifungal protein. Each trial was performed using CAA as the only comparative media. All points are presented as a percentage of growth normalized from a theoretical maximum taken from control samples lacking $\mathrm{YvgO}$ antifungal. Data points are means of triplicate trials given with standard deviations about the mean

YvgO Efficacy as Dictated by Incubation Media pH

Figure 1 (B. fulva, top; C. albicans, bottom) depicts the graphical illustration of the YvgO-mediated susceptibility of each indicator from $\mathrm{pH} 3$ to 8 , using non-supplemented CAA. Illustrations such as this offer a visual assessment of both the efficacy $\left(\mathrm{EC}_{50}\right.$ and $\left.\mathrm{MIC}\right)$ and antifungal/indicator association (slope). The corresponding quantitative account of these parameters is found at the top of Tables 1 ( $B$. fulva) and 2 (C. albicans). B. fulva response shows 
Table 1 Nonlinear regression analysis of $B$. fulva $\mathrm{H} 25$ susceptibility to $\mathrm{YvgO}$ under variable nutrient conditions

\begin{tabular}{|c|c|c|c|c|c|}
\hline Media & Condition & $\begin{array}{l}\text { Visual MIC } \\
(\mu \mathrm{g} / \mathrm{ml})\end{array}$ & $\begin{array}{l}\text { XTT MIC } \\
(\mu \mathrm{g} / \mathrm{ml})\end{array}$ & $\mathrm{EC}_{50}^{\mathrm{b}}\left(95 \% \mathrm{CI}^{\mathrm{c}}, \mu \mathrm{g} / \mathrm{ml}\right)$ & $\begin{array}{l}\text { Slope (95\% CI, } \\
\text { absolute value) }\end{array}$ \\
\hline \multirow[t]{6}{*}{$\mathrm{CAA}^{\mathrm{d}}$, no supplement } & $\mathrm{pH} 3$ & 3.13 & 1.56 & $0.864(0.837-0.892)$ & $2.153(1.991-2.314)$ \\
\hline & $\mathrm{pH} 4$ & 3.13 & 1.56 & $0.570(0.564-0.575)$ & $1.227(1.194-1.259)$ \\
\hline & $\mathrm{pH} 5$ & 3.13 & 1.56 & $0.446(0.391-0.508)$ & $1.145(0.877-1.414)$ \\
\hline & $\mathrm{pH} 6$ & 3.13 & 1.56 & $0.514(0.459-0.576)$ & $1.158(0.943-1.373)$ \\
\hline & $\mathrm{pH} 7$ & 3.13 & 1.56 & $0.411(0.392-0.431)$ & $0.775(0.706-0.844)$ \\
\hline & $\mathrm{pH} 8$ & 6.25 & 6.25 & $1.700(1.675-1.726)$ & $0.882(0.834-0.931)$ \\
\hline \multirow[t]{6}{*}{ CAA $+20 \mathrm{~g} / \mathrm{L}$ mannose } & $\mathrm{pH} 3$ & 3.13 & 1.56 & $0.614(0.570-0.662)$ & $1.941(1.430-2.453)$ \\
\hline & $\mathrm{pH} 4$ & 3.13 & 1.56 & $0.551(0.434-0.700)$ & $2.077(1.671-2.483)$ \\
\hline & $\mathrm{pH} 5$ & 3.13 & 1.56 & $0.581(0.482-0.700)$ & $2.637(2.310-2.964)$ \\
\hline & $\mathrm{pH} 6$ & 3.13 & 1.56 & $0.531(0.509-0.555)$ & $1.665(1.487-1.843)$ \\
\hline & $\mathrm{pH} 7$ & 3.13 & 6.25 & $0.762(0.568-1.024)$ & $1.105(0.480-1.550)$ \\
\hline & $\mathrm{pH} 8$ & 6.25 & 6.25 & $0.607(0.586-0.628)$ & $0.617(0.578-0.657)$ \\
\hline \multirow[t]{6}{*}{$\mathrm{PDB}^{\mathrm{e}}$, no supplement } & $\mathrm{pH} 3$ & 3.13 & 3.13 & $0.536(0.399-0.719)$ & $0.572(0.310-0.833)$ \\
\hline & $\mathrm{pH} 4$ & 1.56 & 1.56 & $0.851(0.569-1.274)$ & $1.614(1.202-2.027)$ \\
\hline & pH 5 & 1.56 & 1.56 & $0.636(0.483-0.837)$ & $0.888(0.622-1.154)$ \\
\hline & $\mathrm{pH} 6$ & 1.56 & 1.56 & $0.745(0.721-0.771)$ & $1.562(1.439-1.685)$ \\
\hline & $\mathrm{pH} 7$ & 1.56 & 1.56 & $1.025(0.937-1.121)$ & $3.994(3.394-4.594)$ \\
\hline & $\mathrm{pH} 8$ & 3.13 & 1.56 & $0.669(0.597-0.749)$ & $1.019(0.934-1.105)$ \\
\hline
\end{tabular}

All values represent the average of three independent experiments each performed in triplicate, with a standard deviation about the mean

a Minimum inhibitory concentrations (MIC) were taken as the last dilution of antifungal to show no appreciable increase (5\%) in cell growth over cell-free controls

${ }^{\mathrm{b}} \mathrm{EC}_{50}=$ effective concentration of antifungal required to reduce cell growth by $50 \%$

${ }^{\text {c }} \mathrm{CI}=$ confidence interval

${ }^{\mathrm{d}}$ CAA $=$ Casamino acids minimal media as described in text

${ }^{\mathrm{e}} \mathrm{PDB}=$ standard potato dextrose agar

significant deviations in $\mathrm{EC}_{50}$ at $\mathrm{pH} 8(\alpha=0.01)$ and $\mathrm{pH} 3$ $(\alpha=0.05)$. This increase in $\mathrm{pH}$ was correlated $(\alpha=0.05)$ with decreasing $\mathrm{YvgO}$ association, which was further correlated $(\alpha=0.05)$ to decreases in cellular proliferation rate. While $C$. albicans failed to show $\mathrm{pH}$-mediated differences in susceptibility, significantly decreased slopes $(\alpha=0.05)$ and MICs $(\alpha=0.01)$ were observed when compared to B. fulva.

YvgO Efficacy Due to Media and Carbohydrate Supplement

Variations in carbohydrate concentration were not significantly different. Tables 1 and 2 also describes the nonlinear regression analysis for $B$. fulva and $C$. albicans, respectively, as dictated by media supplementation. B. fulva incubated in PDB or CAA media supplemented with glucose or mannose (both 5 and $20 \mathrm{~g} / \mathrm{L}$ ) had no statistically significant changes in susceptibility over non-supplemented controls at any $\mathrm{pH}$ tested. As these supplements did not appreciably alter the growth rate of B. fulva, a correlation between cellular proliferation and antifungal concentration was not observed. Furthermore, when incubated in carbohydrate-rich media, the previously observed correlation between media $\mathrm{pH}$ and antifungal association was lost, most likely due to observed normalized growth rates.

The data sets for $C$. albicans are more informative. There is a distinct alteration in both $\mathrm{YvgO}$ efficacy and association as the carbohydrate source was varied. The base CAA media lacking a carbohydrate supplement displayed the poorest $\mathrm{YvgO}$ efficacy (Fig. 1b) along with the poorest cellular proliferation rate. Mannose-supplemented media increased the efficacy approximately fourfold, while the association between the antifungal and yeast remained unchanged. There was a far better increase in $\mathrm{YvgO}$ association when the CAA media was supplemented with D-glucose. A visual interpretation of the differences between the mannose supplement (Fig. 2a) and the D-glucose supplement (Fig. 2b) is noteworthy. However, the strongest association and efficacy against $C$. albicans was observed with PDB (Fig. 2c). In this case, the $\mathrm{EC}_{50}$ and MIC decreased significantly $(\alpha=0.01)$ while the slopes were improved over non-supplemented and mannose- 
Table 2 Nonlinear regression analysis of C. albicans 3153A susceptibility to $\mathrm{YvgO}$ under variable nutrient conditions

\begin{tabular}{|c|c|c|c|c|c|}
\hline Media & Condition & $\begin{array}{l}\text { Visual MIC } \\
(\mu \mathrm{g} / \mathrm{ml})\end{array}$ & $\begin{array}{l}\text { XTT MIC } \\
(\mu \mathrm{g} / \mathrm{ml})\end{array}$ & $\mathrm{EC}_{50}{ }^{\mathrm{b}}\left(95 \% \mathrm{CI}^{\mathrm{c}}, \mu \mathrm{g} / \mathrm{ml}\right)$ & $\begin{array}{l}\text { Slope (95\% CI, } \\
\text { absolute value) }\end{array}$ \\
\hline \multirow[t]{6}{*}{$\mathrm{CAA}^{\mathrm{d}}$, no supplement } & $\mathrm{pH} 3$ & 1,600 & 1,600 & $66.46(51.38-85.96)$ & $0.280(0.232-0.329)$ \\
\hline & $\mathrm{pH} 4$ & 1,600 & 1,600 & $199.7(185.0-215.6)$ & $0.345(0.316-0.374)$ \\
\hline & $\mathrm{pH} 5$ & 800 & 800 & $130.9(115.6-148.1)$ & $0.308(0.280-0.337)$ \\
\hline & $\mathrm{pH} 6$ & 800 & 800 & $207.1(192.7-222.5)$ & $0.698(0.626-0.770)$ \\
\hline & $\mathrm{pH} 7$ & 1,600 & 1,600 & $304.5(230.7-401.9)$ & $0.275(0.235-0.316)$ \\
\hline & $\mathrm{pH} 8$ & 1,600 & 1,600 & $68.18(60.86-76.37)$ & $0.265(0.243-0.287)$ \\
\hline \multirow[t]{6}{*}{$\mathrm{CAA}+20 \mathrm{~g} / \mathrm{L}$ mannose } & $\mathrm{pH} 3$ & 800 & 800 & $48.23(44.22-52.62)$ & $0.316(0.282-0.349)$ \\
\hline & $\mathrm{pH} 4$ & 400 & 200 & $18.37(15.35-21.99)$ & $0.338(0.296-0.380)$ \\
\hline & $\mathrm{pH} 5$ & 200 & 200 & $17.94(15.66-20.54)$ & $0.350(0.324-0.377)$ \\
\hline & $\mathrm{pH} 6$ & 200 & 200 & $40.04(17.93-42.26)$ & $0.558(0.506-0.610)$ \\
\hline & $\mathrm{pH} 7$ & 200 & 200 & $23.68(21.61-25.94)$ & $0.562(0.518-0.606)$ \\
\hline & $\mathrm{pH} 8$ & 200 & 200 & $14.84(13.15-16.76)$ & $0.517(0.404-0.630)$ \\
\hline \multirow[t]{6}{*}{ CAA $+20 \mathrm{~g} / \mathrm{L}$ D-glucose } & $\mathrm{pH} 3$ & 50 & 50 & $17.01(16.68-17.36)$ & $1.920(1.818-2.021)$ \\
\hline & $\mathrm{pH} 4$ & 100 & 50 & $23.80(22.09-25.68)$ & $0.796(0.692-0.901)$ \\
\hline & $\mathrm{pH} 5$ & 100 & 100 & $37.88(28.97-49.53)$ & $0.544(0.375-0.712)$ \\
\hline & pH 6 & 100 & 100 & $48.06(46.56-49.61)$ & $0.852(0.782-0.922)$ \\
\hline & pH 7 & 100 & 100 & $51.25(50.00-52.53)$ & $1.549(1.461-1.636)$ \\
\hline & $\mathrm{pH} 8$ & 100 & 100 & $36.95(34.88-39.15)$ & $0.959(0.888-1.029)$ \\
\hline \multirow[t]{6}{*}{$\mathrm{PDB}^{\mathrm{e}}$, no supplement } & $\mathrm{pH} 3$ & 50 & 50 & $19.12(15.84-23.08)$ & $0.698(0.554-0.841)$ \\
\hline & $\mathrm{pH} 4$ & 50 & 50 & $22.43(21.66-23.21)$ & $1.197(1.120-1.273)$ \\
\hline & $\mathrm{pH} 5$ & 25 & 25 & $8.372(5.485-11.78)$ & $0.651(0.450-0.852)$ \\
\hline & $\mathrm{pH} 6$ & 25 & 25 & $10.56(6.478-17.20)$ & $0.708(0.450-0.966)$ \\
\hline & $\mathrm{pH} 7$ & 25 & 25 & $12.57(9.556-16.53)$ & $0.891(0.616-1.166)$ \\
\hline & $\mathrm{pH} 8$ & 25 & 25 & $9.957(7.677-12.91)$ & $1.394(0.322-2.466)$ \\
\hline
\end{tabular}

All values represent the average of three independent experiments each performed in triplicate, with a standard deviation about the mean

${ }^{a}$ Minimum inhibitory concentrations (MIC) were taken as the last dilution of antifungal to show no appreciable increase (5\%) in cell growth over cell-free controls

${ }^{\mathrm{b}} \mathrm{EC}_{50}=$ effective concentration of antifungal required to reduce cell growth by $50 \%$

${ }^{c} \mathrm{CI}=$ confidence interval

${ }^{\mathrm{d}} \mathrm{CAA}=$ Casamino acids minimal media as described in text

${ }^{\mathrm{e}} \mathrm{PDB}=$ standard potato dextrose agar

supplemented CAA ( $\alpha=0.01)$. Not surprisingly, a correlation between efficacy and proliferation rate is observed $(\alpha=0.01)$ as the growth rate of $C$. albicans increases throughout this series. Interestingly, TSB (commercially formulated with $5 \mathrm{~g} / \mathrm{L}$ glucose) displayed similar efficacy to CAA supplemented with glucose, while dextrose-supplemented CAA did not perform as well as PDB (commercially formulated with $20 \mathrm{~g} / \mathrm{L}$ dextrose).

In effect, the most efficacious response to $\mathrm{YvgO}$ occurred when solution conditions favored rapid indicator proliferation. In B. fulva, at higher $\mathrm{pH}$ values, growth was impeded and the efficacy of $\mathrm{YvgO}$ diminished, even though the association between $\mathrm{YvgO}$ and indicator remained generally unchanged. When offered a media with a carbohydrate source as opposed to a starvation-style media, $C$. albicans grew markedly faster, was more strongly associated with $\mathrm{YvgO}$, and became more susceptible. While mannose conferred a faster cellular proliferation rate that correlated with increased susceptibility, the addition of the preferentially metabolized D-glucose [28] resulted in the most robust proliferation rate and strongest antifungal efficacy. This mirrors other lines of research indicating that glucose, as opposed to mannose, is primarily responsible for cell growth, metabolism and other regulatory factors in many strains of yeast $[17,19,25]$.

Ionic Strength Considerations

Along with changes in solution $\mathrm{pH}$, the ionic strength of the surrounding matrix can influence the electrostatic interactions between a protein antagonist such as $\mathrm{YvgO}$ and the cell surface of its intended target $[1,12]$. For toxins that 


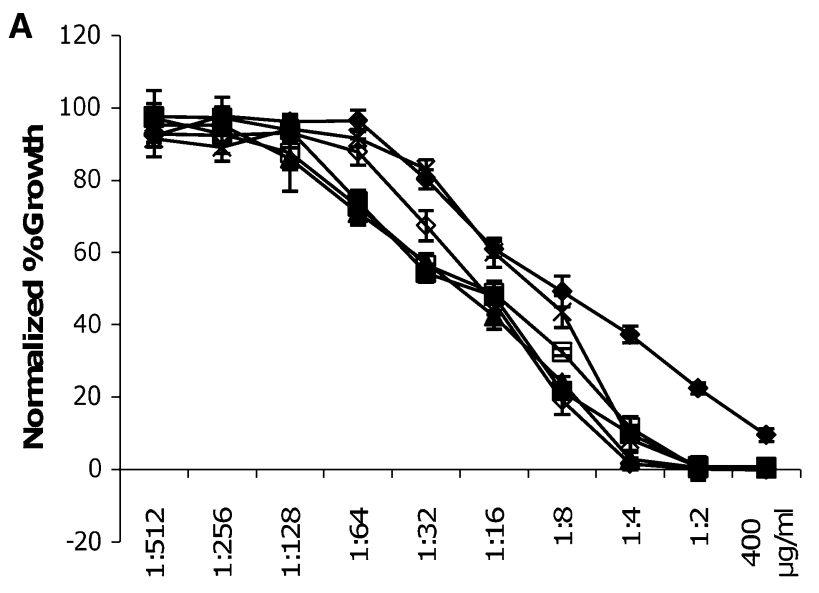

Antifungal Dilution

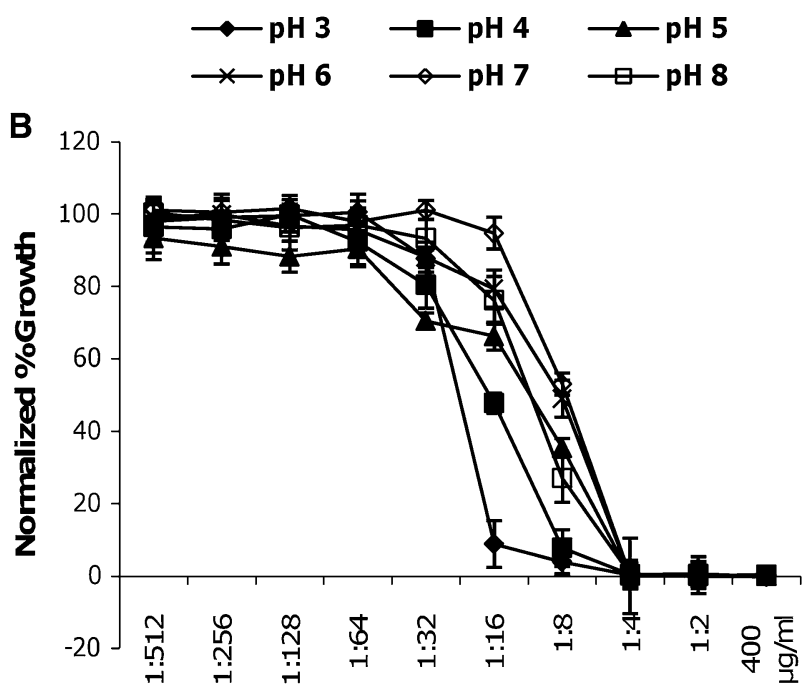

Antifungal Dilution

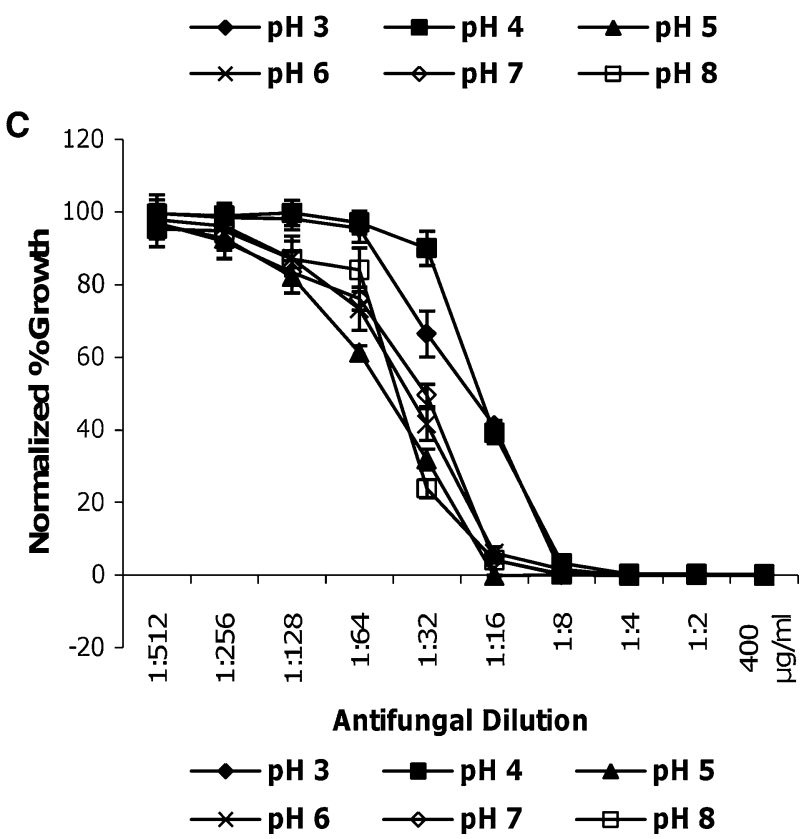

4Fig. 2 XTT-determined growth curves as influenced by alterations in media and carbohydrate supplement generated by C. albicans 3153A exposed to serially diluted additions of the $\mathrm{YvgO}$ antifungal protein. a CAA supplemented with $20 \mathrm{~g} / \mathrm{L}$ mannose; b CAA supplemented with $20 \mathrm{~g} / \mathrm{L}$ D-glucose; c potato dextrose broth (PDB). All points are presented as a percentage of growth normalized from a theoretical maximum taken from control samples lacking YvgO antifungal. Data points are the average of three independent experiments each performed in triplicate, with a standard deviation about the mean

utilize such an initial mode of attachment, disrupting this process would subsequently affect the adsorption and toxicity to the target cell. Assessments were difficult above an ionic strength $>100 \mathrm{mM}$ as indicator growth suffered and required increased incubation time to achieve reliable results. Media tested at physiologically relevant conditions of $\mathrm{pH}$ and ionic strength resulted in a similar efficacy against each indicator. At $\mathrm{pH}$ 6, there were no statistically relevant alterations in $\mathrm{EC}_{50}$ or MIC values when comparing indicator susceptibility in media of varying ionic strength, with or without carbohydrate supplementation. Regardless of carbohydrate supplementation, under acidic conditions ( $\mathrm{pH}$ 3.5), an increased ionic strength resulted in a reduced rate of growth, which in turn, resulted in moderately reduced slopes $(\alpha=0.05)$. In general, increasing ionic strength typically resulted in a decreased association between $\mathrm{YvgO}$ and its target (i.e., decreased slope). As this could have consequences for cell wall attachment or internalization, several lines of inquiry are currently underway.

\section{XTT Optimization for $\mathrm{pH}-$ Variable Matrices}

The XTT metabolic assay provided a great deal of information relevant for this study but suffered from a limited utility. In order to expand the $\mathrm{pH}$ range and better reflect the varied chemistries seen in food-based matrices, a $\mathrm{pH}$ modification step needed to be added and thoroughly validated. Furthermore, the assay needed to be validated for the novel use of a proteinaceous antimicrobial agent with a potentially $\mathrm{pH}$-sensitive efficacy depending upon the toxin's $\mathrm{pK}_{\mathrm{a}}$ and its ability to interact with specific microbial indicators. The initial optimization strategy was adapted from work performed with amphotericin B and itraconazole against specific Aspergillus spp. [22]. An analysis of the indicator density, XTT/menadione concentration, and incubation times that led to the described optimized method is provided in supplemental Figures S1, S2, and S3. The specific conditions chosen (Fig. 3) conferred the strongest signals and lowest standard deviations for the current study. The optimization protocol, when repeated with other proteinaceous antimicrobials (i.e., bacteriocins) against different indicators (i.e., bacilli, lactobacilli), is easily customized for alternate toxin/microbe combinations 
Fig. 3 Optimized XTT method parameters for $\mathrm{YvgO}$-based efficacy trials against $B$. fulva $\mathrm{H} 25$ and $C$. albicans 3153A.

The top shows the concurrent optimization of XTT and menadione response to $B$. fulva (a) or C. albicans (b) indicator. The bottom illustrates the response of the idealized XTT concentration across varying concentrations of menadione and initial spore/cell densities for B. fulva (c) and C. albicans (d). These trials utilized optimized indicator incubation times of 24 and $6 \mathrm{~h}$ for B. fulva and $C$. albicans, respectively, and XTT/menadione exposure incubation times of 120 and $30 \mathrm{~min}$ for $B$. fulva and $C$. albicans, respectively. Shaded areas indicate the chosen parameters used in the current study. The complete optimization protocol can be found by referring to supplemental Figures. 1-3
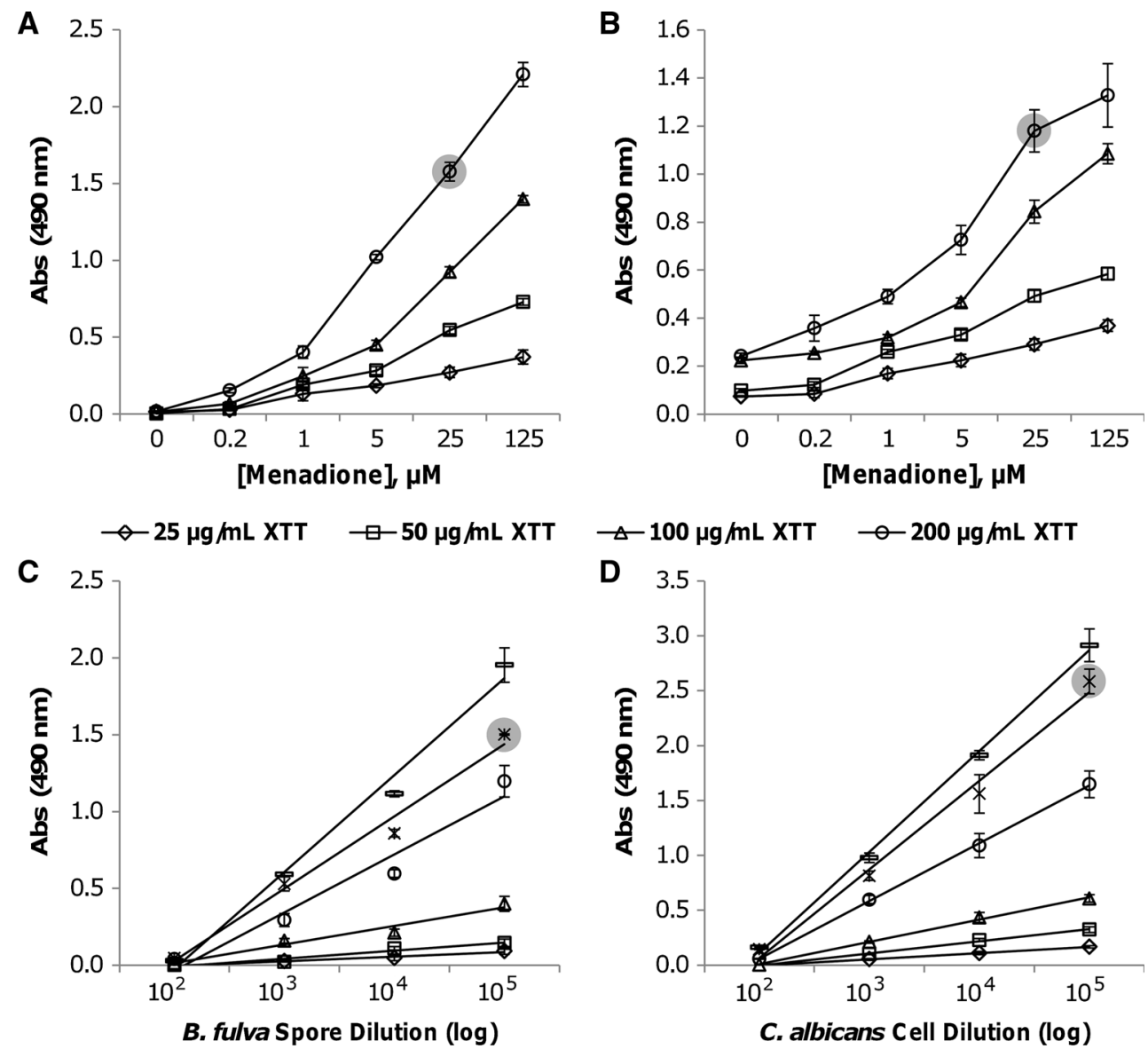

$\triangle 100 \mu \mathrm{g} / \mathrm{mL}$ XTT $\bigcirc 200 \mu \mathrm{g} / \mathrm{mL}$ XTT

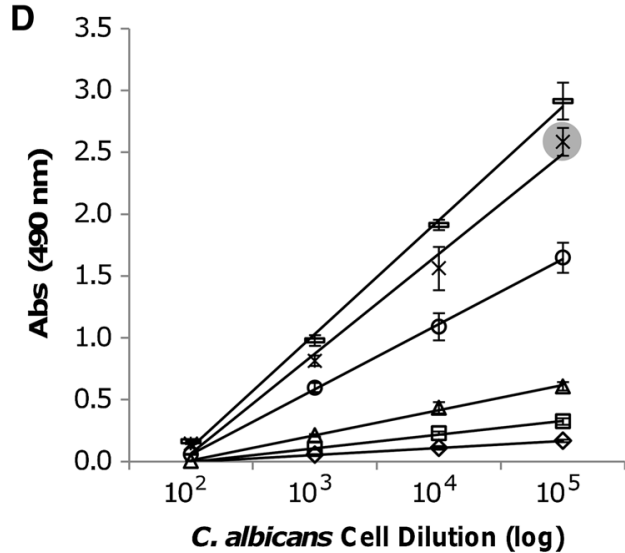

$\diamond 0 \mu \mathrm{M}$ Menadione o5.0 $\mu \mathrm{M}$ Menadione $\square 0.2 \mu \mathrm{M}$ Menadione * $25 \mu \mathrm{M}$ Menadione $\triangle 1.0 \mu M$ Menadione $-125 \mu \mathrm{M}$ Menadione and under various physiological and food-based matrices. This utility is further expanded with post incubation modification of solution $\mathrm{pH}$, as described below.

At lower $\mathrm{pH}$ values, reduced XTT is protonated and fails to give an appreciable signal at any visible wavelength (Fig. 4a, B. fulva; c, C. albicans) even though there is sufficient indicator growth up to $\mathrm{pH} 8$ (Fig. 4b, B. fulva; d, C. albicans). At a higher $\mathrm{pH}$, the increased matrix background signal becomes problematic. While the $\mathrm{pH}$ buffer can be introduced either prior to or after XTT/menadione addition, the timing of the addition was not important as each resulted in a complete recovery of XTT absorbance, regardless of initial incubation $\mathrm{pH}$ (Fig. 4, right). In this fashion, XTT can be a reliable indicator of the remaining cell population after $\mathrm{YvgO}$ exposure, while normalizing the reduced XTT signal to its maximum absorbance. Furthermore, under these conditions the signal due to XTT absorbance was statistically similar to the indicator growth determined visually by simple broth dilution methods. Therefore, from a method development standpoint, this study offers the added benefit of expanding the use of the
XTT assay as a means for the rapid metabolic screening of several quantitative metrics of antimicrobial efficacy, including in vitro testing at variable matrix $\mathrm{pH}$ (Fig. 4).

\section{Concluding Remarks}

The biological activity of YvgO appears similar to other cytotoxic compounds that exploit upregulated mechanisms of cellular metabolism and growth observed in rapidly proliferating cells. The relationship between cellular proliferation and cytotoxicity is well documented in areas concerning chemotherapy and cell cycle metabolism [29].

Already shown to be adaptable to fungi [22] and yeast such as Candida spp. [3, 15], using the modifications to the XTT assay, a direct quantification of the proliferationdependent efficacy of $\mathrm{YvgO}$ across all viable solution $\mathrm{pHs}$ is described. As the XTT assay relies on metabolically active cells to measure cytotoxicity, a strong correlation between YvgO efficacy and cellular proliferation can be established. The expansion of this assay to include a wider 
Fig. 4 XTT assay optimization for $\mathrm{pH}$-variable matrices. a $B$. fulva $\mathrm{H} 25$ and c $C$. albicans 3153A: The problem. The dark bars indicate the background absorbance of cell-free media supplemented with the optimized concentrations of XTT and menadione. The light gray bars indicate the XTT absorbance due to cell growth. The traced line shows the unacceptably decreasing usable signal under the varying $\mathrm{pH}$ conditions. b $B$. fulva and $\mathbf{d} C$. albicans: The solution. The dark bars now represent backgroundcorrected unbuffered signal generated by XTT reduction by either B. fulva $\mathrm{H} 25$ (b) or $C$. albicans (d) across the $\mathrm{pH}$ range from 3 to 10. The light gray bars, also background-corrected, show the same conditions as altered by the addition of the $\mathrm{pH}$ 6.2 buffer prior to spectroscopic analysis. The traced line shows the cellular growth as read via spectroscopic absorbance at $600 \mathrm{~nm}$
A
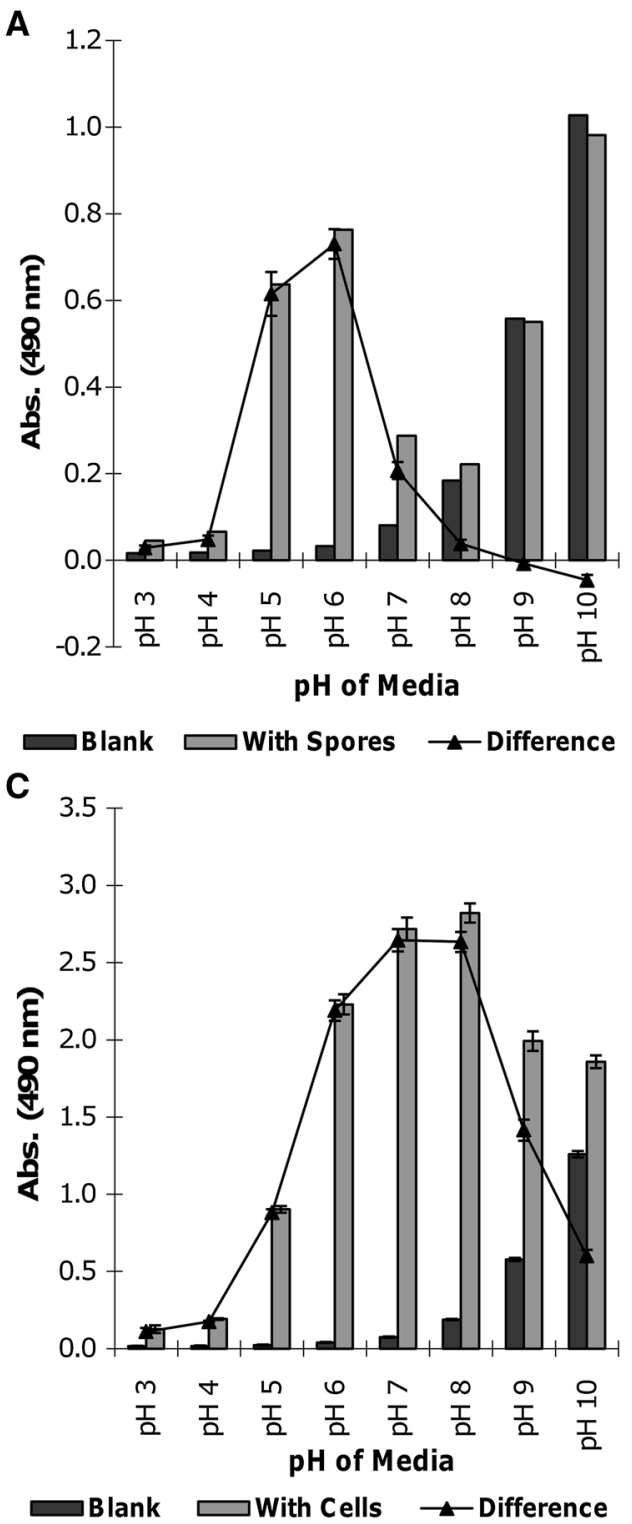

B

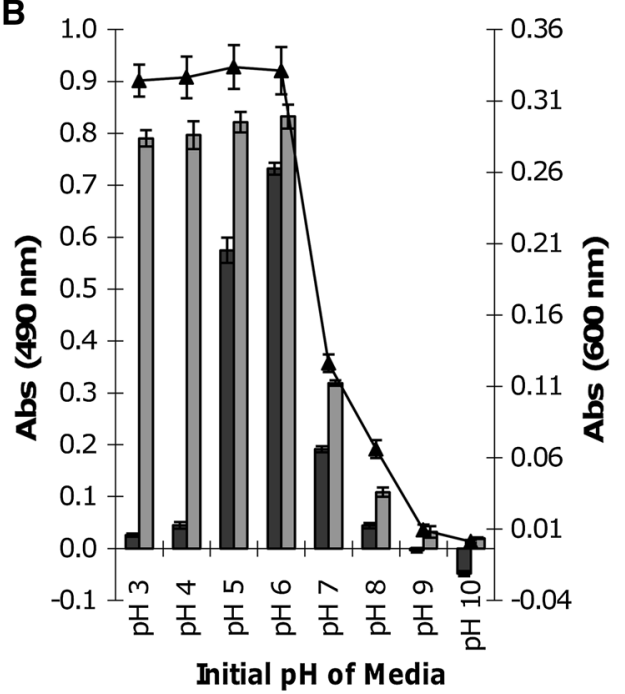

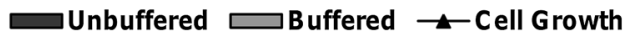

D

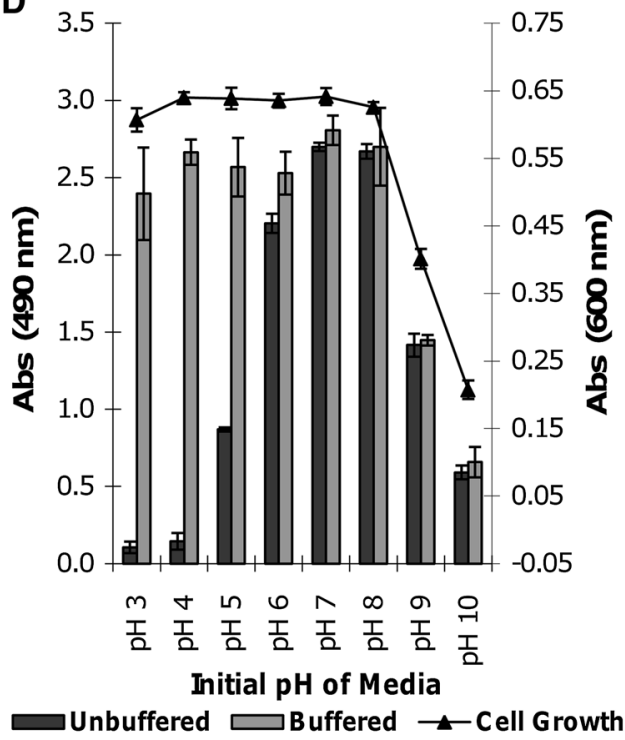

$\mathrm{pH}$ range will be of interest to the fruit juice and beverage industries where heat-resistant molds are often a concern in various acidic commodities [27].

This study offers the first considerations concerning the biological activity for $\mathrm{YvgO}$ based on cellular proliferation correlations. As a complement to these initial studies, collaborative work to elucidate YvgO's tertiary structure based on 3D NMR analysis in order to compare structureactivity relationships is forthcoming. Widening the search for natural antimicrobials and preservatives is imperative. Proteinaceous compounds of this sort offer unique selectivity that may be exploited in several scientific disciplines. Due to its robust nature and efficacy, clinical and industrial applications for the $\mathrm{YvgO}$ protein are promising. In the food industry, YvgO could see significance in liquid-based commodities that suffer from spoilage to due heat-resistant molds such as $B$. fulva or contamination from mycotoxin producing molds such as Penicillium spp. and Aspergillus spp. As YvgO is efficacious in model physiological solutions, an inquiry into potential cross-sensitivity to mammalian cell lines and synergistic interactions with established antifungal pharmaceuticals is currently underway. Furthermore, in an effort to reduce the effective dosage of relatively toxic antifungal pharmaceuticals, the role of $\mathrm{YvgO}$ as a potential complementary cofactor for established antifungal therapies is also being explored.

Acknowledgments Funding for this research was provided by the United States Department of Agriculture, National Integrated Food Safety Initiative (USDA-NIFSI) grant \#2008-51110-0688 well as the National Science Foundation Graduate Research Fellowship Program. The authors would also like to thank the Cornell University Proteomics and Mass Spectrometry Core Facility and the Proteomics and 
Mass Spectrometry Facility at the Donald Danforth Plant Science Center for their technical assistance regarding initial YvgO purification.

Conflict of interest The authors declare no conflict of interest.

\section{References}

1. Ben-Tal N, Honig B, Miller C, McLaughlin S (1997) Electrostatic binding of proteins to membranes. Theoretical predictions and experimental results with charybdotoxin and phospholipid vesicles. Biophys J 73(4):1717-1727

2. Cantón E, Espinel-Ingroff A, Pemán J (2009) Trends in antifungal susceptibility testing using CLSI reference and commercial methods. Expert Rev Anti Infect Ther 7:107-119

3. Chamilos G, Lewis RE, Kontoyiannis DP (2006) Inhibition of Candida parapsilosis mitochondrial respiratory pathways enhances susceptibility to caspofungin. Antimicrob Agents Chemother 50:744-747

4. Clancy CJ, Nguyen MH (1997) Comparison of a photometric method with standardized methods of antifungal susceptibility testing of yeasts. J Clin Microbiol 35:2878-2882

5. Clinical and Laboratory Standards Institute (CLSI) (2008) Reference method for broth dilution antifungal susceptibility testing of filamentous fungi; approved standard, $2^{\text {nd }}$ ed. CLSI document M38-A2. 28(16): 1-35

6. Clinical and Laboratory Standards Institute (CLSI) (2008) Reference method for broth dilution antifungal susceptibility testing of yeasts; approved standard, $3^{\text {rd }}$ ed. CLSI document M27-A3. 28(14): $1-25$

7. Dent ME, Hubbold L, Radford H, Wilson AP (1996) Use of XTT for quantitating clonogenic growth in soft agar. Cytotechnology 18:219-225

8. DeSilva B, Smith W, Weiner R, Kelly M, Smolec J, Lee B, Khan M, Tacey R, Hill H, Celniker A (2003) Recommendations for the bioanalytical method validation of ligand-binding assays to support pharmacokinetic assessments of macromolecules. Pharm Res 20:1885-1900

9. Findlay JWA, Dillard RF (2007) Appropriate calibration curve fitting in ligand binding assays. AAPS J 9:E260-E267

10. Finney DJ (1976) Radioligand assay. Biometrics 32:721-740

11. Ghannoum MA, Rice LB (1999) Antifungal agents: mode of action, mechanisms of resistance, and correlation of these mechanisms with bacterial resistance. Clin Microbiol Rev 12:501-517

12. Hartvig RA, van de Weert M, Østergaard J, Jorgensen L, Jensen $H$ (2011) Protein adsorption at charged surfaces: the role of electrostatic interactions and interfacial charge regulation. Langmuir 27(6):2634-2643

13. Hawser SP, Norris H, Jessup CJ, Ghannoum MA (1998) Comparison of a 2,3-bis(2-methoxy-4-nitro-5-sulfophenyl)-5-[(phenylamino)carbonyl]-2H-tetrazolium hydroxide (XTT) colorimetric method with the standardized National Committee for Clinical Laboratory Standards method of testing clinical yeast isolates for susceptibility to antifungal agents. J Clin Microbiol 36:1450-1452

14. Kanafani ZA, Perfect JR (2008) Antimicrobial resistance: resistance to antifungal agents: mechanisms and clinical impact. Clin Infect Dis 46:120-128
15. Kuhn DM, Balkis M, Chandra J, Mukherjee PK, Ghannoum MA (2003) Uses and limitations of the XTT assay in studies of Candida growth and metabolism. J Clin Microbiol 41:506-508

16. Lee SM, Kim JM, Jeong J, Park YK, Bai GH, Lee EY, Lee MK, Chang CL (2007) Evaluation of the Broth Microdilution Method Using 2,3-Diphenyl-5-thienyl-(2)-tetrazolium Chloride for Rapidly Growing Mycobacteria Susceptibility Testing. J Korean Med Sci 22:784-790

17. Lemaire K, Van de Velde S, Van Dijck P, Thevelein JM (2004) Glucose and sucrose act as agonist and mannose as antagonist ligands of the $G$ protein-coupled receptor Gpr1 in the yeast Saccharomyces cerevisiae. Mol Cell 16:293-299

18. Liu M, Seidel V, Katerere DR, Gray AI (2007) Colorimetric broth microdilution method for the antifungal screening of plant extracts against yeasts. Methods 42:325-329

19. Maidan MM, Thevelein JM, Van Dijck P (2005) Carbon source induced yeast-to-hypha transition in Candida albicans is dependent on the presence of amino acids and on the G-protein-coupled receptor Gpr1. Biochem Soc Trans 33:291-293

20. Manns DC, Churey JJ, Worobo RW (2012) Functional assignment of $\mathrm{YvgO}$, a novel set of purified and chemically characterized proteinaceous antifungal variants produced by Bacillus thuringiensis SF361. Appl Environ Microb 78(8):2543-2552

21. Meletiadis J, Meis JF, Mouton JW, Donnelly JP, Verweij PE (2000) Comparison of NCCLS and 3-(4, 5-dimethyl-2-Thiazyl)2,5-diphenyl-2H-tetrazolium bromide (MTT) methods of in vitro susceptibility testing of filamentous fungi and development of a new simplified method. J Clin Microbiol 38:2949-2954

22. Meletiadis J, Mouton JW, Meis JF, Bouman BA, Donnelly JP, Verweij PE, Eurofung Network (2001) Colorimetric assay for antifungal susceptibility testing of Aspergillus species. J Clin Microbiol 39:3402-3408

23. Paul KD, Shoemaker RH, Boyd MR (1988) The synthesis of XTT: a new tetrazolium reagent that is bioreducible to a water soluble formazan. J Heterocycl Chem 25:911-914

24. Perea S, Patterson TF (2002) Antifungal Resistance in Pathogenic Fungi. Clin Infect Dis 35:1073-1080

25. Rodaki A, Bohovych IM, Enjalbert B, Young T, Odds FC, Gow NAR, Brown AJP (2009) Glucose promotes stress resistance in the fungal pathogen Candida albicans. Mol Biol Cell 20:4845-4855

26. Tellier R, Kajden M, Grigoriew GA, Campbell I (1992) Innovative endpoint determination system for antifungal susceptibility testing of yeasts. Antimicrob Agents Chemother 36:1619-1625

27. Tournas VH, Heeres J, Burgess L (2006) Moulds and yeasts in fruit salads and fruit juices. Food Microbiol 23:684-688

28. Towle HC (2005) Glucose as a regulator of eukaryotic gene transcription. Trends Endocrinol Metab 16:489-494

29. Valeriote F, van Putten L (1975) Proliferation-dependent cytotoxicity of anticancer agents: a review. Cancer Res 35(10):26192630

30. Wang G, Manns DC, Guron GKP, Churey JJ, Worobo RW (2014) Large-scale purification, characterization, and spore outgrowth inhibitory effect of thurincin $\mathrm{H}$, a bacteriocin produced by Bacillus thuringiensis SF361. Probiotics Antimicrob Proteins 6(2):105-113 